ORIGINAL ARTICLE

\title{
Cost effectiveness of a dealer's intervention in retrofitting rollover protective structures
}

\author{
M L Myers, H P Cole, S C Westneat
}

Injury Prevention 2005;11:169-173. doi: 10.1136/ip.2004.007039

See end of article for authors' affiliations

Correspondence to:

Mr M L Myers, 1293

Berkeley Road, Avondale

Estates, GA 30002-1517

USA; melmyers@bellsouth. net

Accepted 12 October 2004
Objective: To evaluate the cost effectiveness of a 4.5 year education campaign that promoted farmers' adoption of rollover protective structures (ROPS) to prevent tractor overturn injuries.

Design: Randomized controlled trial, decision analysis, and cost effectiveness analysis.

Setting: One treatment county and one control county in the State of Kentucky.

Intervention: A campaign by a local tractor and equipment dealership to encourage farmers to purchase and install ROPS and seatbelt retrofit kits for older tractors.

Main outcome measures: Number of injuries averted and cost per injury averted.

Results: The dealership's 4.5 year intervention was shown to potentially reduce both fatal $(0.26)$ and nonfatal (1.50) injuries by $2.6 \%$ in its county over the intervention period using a 20 year analytic horizon. When extrapolated statewide, 6.7 lives would be saved and 39 non-fatal injuries would be averted over the combined 24.5 year combined intervention period and analytic horizon. The intervention for this period was cost effective with a "savings" of $\$ 35713$ per injury (fatal plus non-fatal) averted at a $4 \%$ discount rate.

Conclusions: Tractor manufacturer promotions can influence their dealerships to promote ROPS retrofits by their customers. A manufacturer backed dealer ROPS retrofit campaign was cost effective in reducing overturn related injuries.
$\mathrm{T}$ his article presents a cost effectiveness analysis of an intervention that a Kentucky equipment dealership conducted in its local county. The dealership encouraged farmers to retrofit older tractors with rollover protective structures (ROPS). ${ }^{1}$ ROPS and seatbelts are proven technologies for protecting tractor operators from serious injury or death during tractor overturns. ${ }^{2}$

In 1997, researchers at the University of Kentucky launched a community education program to promote the installation of ROPS and seatbelts on unprotected tractors. The three year intervention was conducted during the 1997-99 period. The study design included an initial and post-intervention telephone survey of a random sample of farmers to evaluate the success of the program in the two treatment counties compared with two control counties. The two intervention counties were geographically distant from each other and from the control counties. ${ }^{1}$ However, in July 1995 a dealership in one control county launched the anomalous intervention that promoted the retrofitting of older tractors with ROPS and seatbelts by farmers. Over the following 4.5 year intervention period, the dealership sold about 11 retrofit kits per year. Before its promotion program the dealership had sold only one to two retrofit kits per year. Most of the farmers who purchased ROPS retrofits before the intervention were motivated more for the sunshade provided by the canopy that they had the dealer attach to the ROPS rather than for the safety provided by the ROPS during an overturn.

The dealership launched its intervention after the death of a customer from a tractor overturn. The customer had attended the dealer's tractor day event, which incorporated an at-cost ROPS retrofit campaign that was encouraged by tractor manufacturers (personal communication from $\mathrm{J}$ Bobbitt, J \& G Equipment to Myers and Cole, 2002). Following the dealer's safety day event the customer purchased a retrofit kit, but deferred installing the ROPS until his summer vacation from his off-farm job. Subsequently in May 1995, as he continued operating his non-ROPS tractor, it overturned and killed him. ${ }^{3}$

The dealership's motivation and success in mounting its own ROPS promotion effort was supported by two earlier events. Firstly, in 1985, tractor manufacturers voluntarily adopted ROPS as standard equipment. Secondly, in 1993, four major manufacturers launched a joint campaign that provided ROPS retrofit kits to farmers at cost through equipment dealers. ${ }^{4}$ The manufacturers urged farm equipment dealers to encourage their customers to retrofit their tractors with ROPS and seatbelts.

As part of its intervention the dealership donated an older non-ROPS tractor for overturn demonstrations. The demonstrations were conducted at the dealership sponsored annual tractor days and additional safety days events conducted by the dealer and other groups in the county. During the demonstrations a dummy seated on the tractor was crushed beneath an overturned tractor (personal communication from J Bobbitt, J \& G Equipment to Myers and Cole, 2002). Farmers with other brands of tractors often asked the dealer where they could obtain ROPS for their tractors.

This emergent intervention became a unique opportunity to evaluate the effect of the dealership campaign for retrofitting tractors with ROPS. Since the initial and postintervention surveys for the original study design were administered to both control counties, it was possible to compare the results of the emergent intervention in the anomalous control county with the true control county that received no intervention (see table 1). The initial intervention survey occurred 1.5 years after the dealer launched its intervention. The post-intervention survey occurred three years later. Both surveys collected information about farmers' degree of contemplating obtaining ROPS protected tractors, their efforts at doing so, and the number of tractors they retrofitted with ROPS or replaced with ROPS equipped

Abbreviations: ROPS, rollover protective structure. 
Table 1 Initial and post-intervention survey results, 1997 and 2000

\begin{tabular}{lll}
\hline Effectiveness factor & $\begin{array}{l}\text { County } \\
\text { Intervention }\end{array}$ & Control \\
\hline Total number of farms & 949 & 1264 \\
Number surveyed & $321(33.8 \%)$ & $322(25.5 \%)$ \\
Number of retrofits reported in survey & 33 & 8 \\
Total number of tractors & 2752 & 3034 \\
Number of tractors with no ROPS & 1879 & 2022 \\
Percentage of tractors retrofitted & $6.0 \%$ & $1.6 \%$ \\
Normal tractor replacement rate per year * & $4.2 \%$ \\
Cost per ROPS installation & $\$ 649$ & $\$ 691$ \\
\hline \multirow{2}{*}{ *Only survey results from the control county were used for the normal } \\
annual tractor replacement rate.
\end{tabular}

tractors for the protective value of the ROPS as opposed to other reasons. The response rate to the telephone surveys was $86 \%$. The survey gathered data for a repeated measures design from large random samples of farmers from each county. ${ }^{1}$

\section{METHOD}

The method used in this study was cost effectiveness analysis that included decision and cost analyses. A decision analysis was used with a decision tree as the principal tool ${ }^{5}$ as shown in figure 1 for which the summary measure was the incremental number of injuries (fatal and non-fatal) averted by the intervention. A cost analysis was used for which the summary measure was the cost per injury averted. ${ }^{6}$ The software Microsoft Excel was used for a spreadsheet analysis as described by Petitti. ${ }^{7}$

\section{DECISION ANALYSIS}

In the event of an overturn, the operator may incur a fatal injury, a non-fatal injury, or no injury with different probabilities under the "Dealer intervention" and "No dealer intervention" strategies. ${ }^{1}$ The framework for the decision analysis included the following key points:

- The audience comprises tractor and ROPS manufacturers and dealers.

- The time frame for the intervention was 4.5 years starting in July 1995 and extending up to January 2000. The initial intervention survey (January 1997) and post-intervention survey (January 2000) covered the last three years of the equipment dealership's emergent intervention. The results from the three year period that the survey covered are assumed to reflect the intervention effect for the 4.5 year period. This assumption has an embedded bias of an elevated baseline, thus the impact of the program is likely greater than the results of this study show.

- The unit of intervention used in this study was 2000 hours of annual tractor operation. This unit is consistent with existing literature and represents 40 hours per week of operation over a 50 week period-a full time work equivalent. ${ }^{8}$ The number of non-ROPS tractors in the intervention and the non-intervention counties were established based upon the initial intervention survey as shown in table 1.

- This population of non-ROPS tractors was reduced annually at the observed tractor replacement rate of $4.2 \%$ per year in the control county over the 20 year analytic horizon for this study. This rate was based upon data from the post-intervention survey.

- The type of analysis was incremental. Thus, it measured the effectiveness of the intervention compared with an alternative; in this case the true control county that received no intervention.

Seven probabilities were used in the decision tree: The annual probability of an overturn per 2000 hours of tractor operation under both strategies (Pr_o) was 0.007604; ${ }^{9}$ The probability of death resulting from an overturn with an ROPS

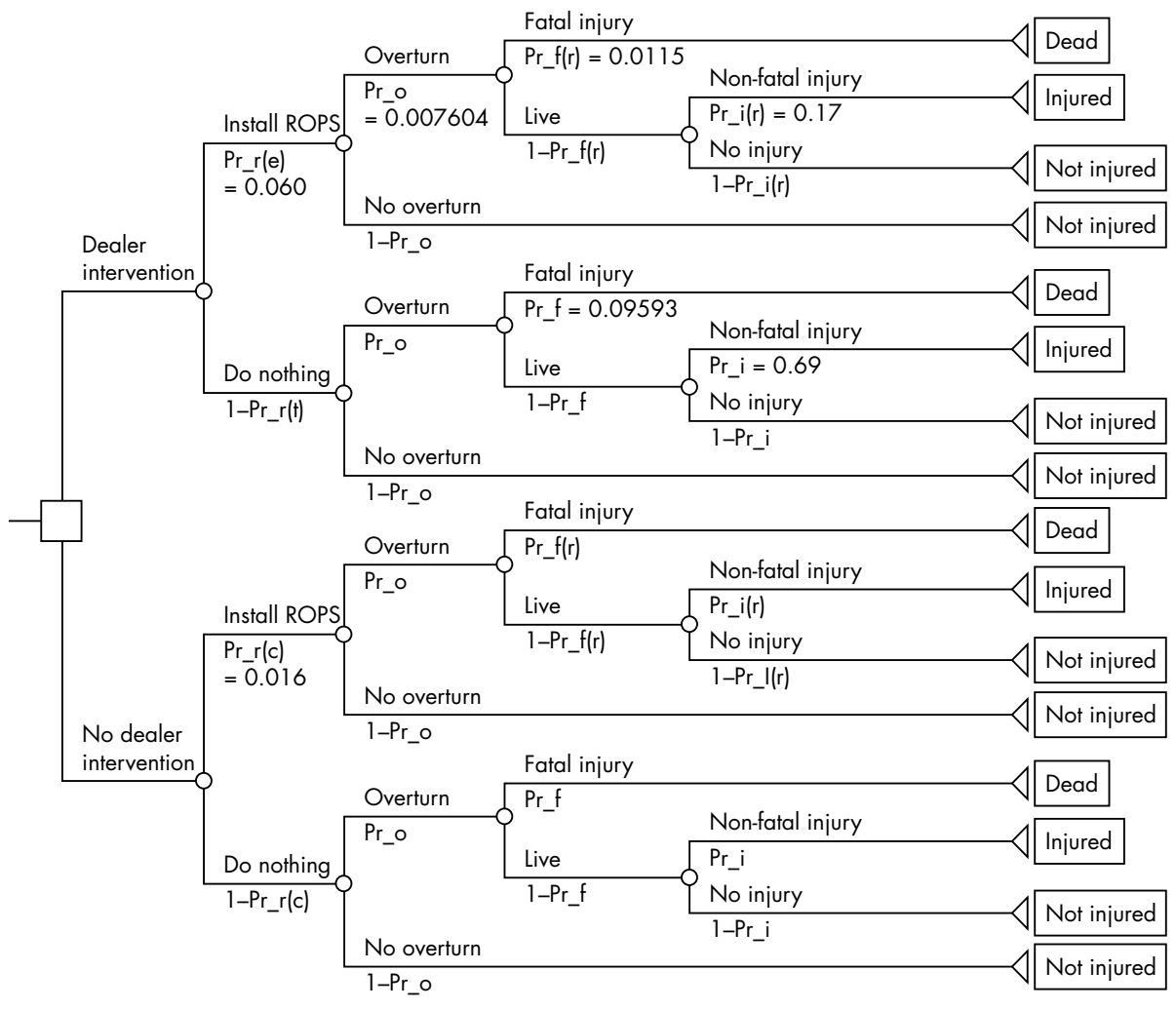

Figure 1 A decision tree that shows two choices - a dealer intervention to promote ROPS retrofits on older tractors and no dealer intervention (control)used in Kentucky, and health outcomes associated with tractor overturns. 
installed $(\operatorname{Pr} \mathrm{f}(\mathrm{r}))$ was $0.0115 ;^{10}$ The probability of death resulting from an overturn without an ROPS installed ( $\operatorname{Pr} f$ ) was $0.09593 ;^{11}$ The probability of a non-fatal injury resulting from an overturn without an ROPS installed, given survival (Pr_i) was 0.69; ${ }^{11}$ The probability of a non-fatal injury resulting from an overturn with an ROPS installed, given survival (Pr_i $(\mathrm{r})$ ) was $0.17 ;^{10}$ The probability of installing an ROPS in the emergent intervention county (Pr_r(e)) was $0.060 ;^{1}$ and the probability of installing an ROPS in the control county $(\operatorname{Pr} r(c))$ was $0.016 .{ }^{1}$ This latter probability differs from another study ${ }^{9}$ because it included tractor replacement decisions made so as to acquire ROPS protection. Through a product of these probabilities, the decision tree provided a result of the number of fatal and non-fatal injuries per 2000 hours of tractor operation.

To derive the number of lives saved for each strategy, the number of non-ROPS tractors was calculated for the intervention county for the year 1997 based upon the number of farms located there (as reported in 1997 Census of Agriculture tables) and the average number of tractors reported per farm in the initial intervention survey. The hours of annual tractor use for non-ROPS tractors, 238 hours, was multiplied times the non-ROPS tractor population to derive the hours of tractor use in the intervention county, which was converted to the equivalent of 2000 hours of use per year for the multiplication calculation described above. ${ }^{8}$ The experiences reported over the three year survey period were extrapolated back over the 4.5 year intervention period, and the ROPS retrofits were assumed to occur proportionately over the 4.5 year intervention period.

\section{COST ANALYSIS}

The cost effectiveness analysis includes net cost based upon the equation below. ${ }^{12}$

Net Cost $=$ Cost $_{\text {intervention }}+$ Cost $_{\text {side effects }}-$ Cost $_{\text {direct }}-$ Cost $_{\text {indirect }}$

The net cost includes the cost of all resources required for the program. The direct (for example, medical) and indirect (for example, productivity losses) costs of the injury averted were subtracted from the intervention cost and side effect cost to derive the net cost. ${ }^{6}$ The cost of the intervention includes the funds expended on the program, the in-kind expenditures made for farmer participation, and the investment farmers made by purchasing an ROPS.

These costs included the donation of a tractor (\$3000) for the demonstrations with a dummy driver, expenses for tractor safety or farm days ( $\$ 200$ each), time donated to and spent at these days (200 hours per event times $\$ 10$ per hour), and the cost of the ROPS retrofits during the intervention period.

The cost of the ROPS was a total of the purchase price, shipping fees, and a one-time installation. For this dealer, the cost per ROPS varied between $\$ 300$ and $\$ 400$, the shipping fee was $\$ 85$ each, and the installation time typically was 2 hours and 10 minutes during which two extra workers were needed to hold the ROPS uprights and top bar in place during bolting. However, because the dealer did not perform all the retrofits, we used the farmers' average cost estimate for ROPS retrofits that we obtained from the post-intervention survey data. Farmers in the intervention county estimated their cost for retrofitting a tractor with an ROPS at an average of $\$ 649$.

In addition, a side effect of the intervention was the cost of an ROPS replacement whenever a tractor overturned, in which the tractor was equipped with an ROPS as a result of the intervention. The cost for these replacements was calculated as \$1072. The costs are summarized in table 2 .

The direct and indirect costs incurred as a result of an occupational injury were based upon those used by Leigh et al. ${ }^{13}$ The framework in the cost analysis included the following key points:

- The analytic horizon included the 4.5 year intervention period plus another 20 years since the injury consequences extended well beyond the ROPS retrofit period.

- The perspective was social in which all costs were included irrespective of who pays them.

- The approach was cost-of-injury (disease) in which the cost of pain and suffering was not included.

- All occupations including farming were used to calculate the costs of an injury, because $59 \%$ of the principle farm operators in Kentucky had jobs off the farm and were thus engaged in non-agricultural employment. ${ }^{14}$ However, agricultural occupations were used in a sensitivity analysis. $^{15}$

- The discount rate of $4 \%$ was used so as to be consistent with the rate used in similar cost effectiveness studies. ${ }^{16}$ This rate lies between that recommended by the $\mathrm{CDC}^{12}$ in 1994 of $5 \%$ and the current recommended rate of $3 \% .{ }^{17}$

- All human life was considered of equal value for a normal lifetime no matter the age. ${ }^{18}$

- US dollars were used as the measure of cost.

Table 2 Cost inventory in 1997 US dollars for the base case intervention county and the agricultural occupations scenario before discounting and inflation adjustment

\begin{tabular}{|c|c|c|c|}
\hline Item & Cost factors & Value & \\
\hline \multicolumn{4}{|c|}{ Cost $_{\text {intervention }}+$ Cost $_{\text {side effects }}$} \\
\hline Older tractor & One donated for overturn demo & $\$ 3000$ & \\
\hline Farm day expenses & Nine farm days at $\$ 200$ each & $\$ 1800$ & \\
\hline In-kind participation & $\begin{array}{l}\text { Two farm days } / \text { year; } 50 \text { people at } 4 \text { hours } \\
\text { at } \$ 10 / \text { hour; } 4.5 \text { years }\end{array}$ & $\$ 18000$ & \\
\hline ROPS investment & 170 ROPS at $\$ 649$ & $\$ 110397$ & \\
\hline ROPS replacement & $\begin{array}{l}\text { Replacement ROPS for overturns over } \\
20 \text { years }\end{array}$ & $\$ 1072$ & \\
\hline \multirow[t]{2}{*}{ Total } & & $\$ 134269$ & \\
\hline & & Agriculture $^{15}$ & $\begin{array}{l}\text { All } \\
\text { occupations }^{1313}\end{array}$ \\
\hline \multicolumn{4}{|l|}{ Costdirect } \\
\hline $\begin{array}{l}\text { Fatal injury } \\
\text { Non-fatal injury }\end{array}$ & $\begin{array}{l}\text { Lifetime medical, insurance administration, } \\
\text { property damage, emergency services, and } \\
\text { third party iniuries }\end{array}$ & $\begin{array}{r}\$ 33853 \\
\$ 1729\end{array}$ & $\begin{array}{r}\$ 33850 \\
\$ 8819\end{array}$ \\
\hline \multicolumn{4}{|l|}{ Costindirect } \\
\hline $\begin{array}{l}\text { Fatal injury } \\
\text { atect }\end{array}$ & Lost earnings, household production, and & $\$ 383695$ & $\$ 682589$ \\
\hline Non-fatal injury & fringe benefits & $\$ 10551$ & $\$ 25028$ \\
\hline
\end{tabular}


Table 3 Results of the analysis of an intervention county as compared with a control county, sensitivity analyses at $0 \%$ discount rate and for agricultural occupations, and as compared with the results of the original two treatment counties

\begin{tabular}{|c|c|c|c|c|c|}
\hline \multirow[b]{2}{*}{ Scenario } & \multirow[b]{2}{*}{ Discount rate } & \multicolumn{2}{|c|}{ Injuries (statewide extrapolation) } & \multicolumn{2}{|c|}{ Cost in US dollars (savings) } \\
\hline & & Fatal & Non-fatal & Total & Per injury averted \\
\hline Intervention & $0 \%$ & $2.20(57.5)$ & $14.5(380.5)$ & - & - \\
\hline Control & $0 \%$ & $\begin{array}{l}2.45 \text { (64.3) } \\
\text { Injuries averted }\end{array}$ & $16.0(419.9)$ & - & - \\
\hline $0 \%$ discount rate & $0 \%$ & $0.26(6.7)$ & $1.50(39.4)$ & $(\$ 101148)$ & (\$57 395) \\
\hline Base case & $4 \%$ & $0.24(6.2)$ & $1.07(28.0)$ & $(\$ 46184)$ & (\$35 713) \\
\hline $8 \%$ discount rate & $8 \%$ & $0.24(6.2)$ & $1.06(27.7)$ & (\$14996) & $(\$ 11526)$ \\
\hline Agricultural & $0 \%$ & $0.26(6.7)$ & 1.50 (39.4) & $\$ 8528$ & $\$ 36993$ \\
\hline Occupations ${ }^{15}$ & $4 \%$ & $0.24(6.2)$ & $1.07(28.0)$ & $\$ 4839$ & $\$ 28344$ \\
\hline Original treatment & $0 \%$ & $0.27(7.0)$ & $1.53(40.0)$ & $\$ 177417$ & $\$ 98652$ \\
\hline counties ${ }^{* 9}$ & $4 \%$ & $0.19(5.0)$ & $1.09(28.6)$ & $\$ 222072$ & $\$ 172657$ \\
\hline
\end{tabular}

\section{RESULTS}

With no intervention, 2.4 deaths and 16 non-fatal injuries could be expected over a 20 year period in the intervention county. When extrapolated statewide, 64 deaths and 420 non-fatal injuries could be expected over the same period.

As shown in table 3, the intervention launched in the dealership's county was effective in reducing these deaths and non-fatal injuries (undiscounted) by 0.26 and 1.50 , respectively. When extrapolated statewide the dealer intervention could be effective at saving 6.7 lives and averting 39 non-fatal injuries over a 20 year period. For the base case scenario at a $4 \%$ discount rate, the "savings" (negative costs) per injury averted was $\$ 35713$. However, at a $0 \%$ discount rate, this savings was raised to $\$ 57395$ per injury averted, and conversely at an $8 \%$ discount rate, the savings was reduced to \$11 526 per injury averted.

For the agricultural occupations scenario, the cost per injury averted of \$28 344 did not show a savings as was the case for all occupations. A cost effectiveness analysis also was calculated for the ROPS promotion effort in two intervention counties conducted by the University of Kentucky and multiple community partners. ${ }^{9}$ The university/community partners' intervention was found to be as effective in preventing fatalities as the local ROPS promotion effort by the tractor dealership in one county. However, the partner intervention effort indicated a net cost for each tractor overturn injury averted as compared to a net savings shown by the dealer's intervention.

\section{CONCLUSION}

Effectiveness was increased nearly fourfold with respect to the number of ROPS that farmers installed on their tractors following the dealer's intervention compared with ROPS retrofits in the control county. The cost effectiveness of the dealership's program at a savings of $\$ 35713$ per injury averted was economically and starkly appealing when compared with similar national results of a cost of $\$ 489373$ per injury averted. ${ }^{16} 19$

Tractor manufacturer's promotions can influence their dealers to promote the retrofitting of tractors with ROPS by their customers. This promotion was the initial stimulus for the dealership to encourage its customers to invest in ROPS retrofits. The manufacturer backed ROPS retrofit campaign by the dealer was cost effective in reducing overturn related injuries.

\section{ACKNOWLEDGEMENTS}

The authors wish to acknowledge that this work was supported by CDC/NIOSH Cooperative Agreements IU50OH07547-01, U06/ CCU412900, and U06/CCU417554. We also are grateful for the assistance and reviews provided by Regina Pana-Cryan, PhD, Senior

\section{Key points}

- A dealer's intervention program for retrofitting ROPS resulted in a net social savings and not a social cost.

- Manufacturer backed ROPS promotions can influence dealers to mount retrofit programs.

- The death of a tractor operator due to an overturn can influence the wider community to invest in ROPS for their own tractors.

Service Fellow, NIOSH/CDC. The University of Kentucky's Office of Research Integrity reviewed and approved the research protocol and the informed consent procedures for the study on an annual basis under IRB Numbers 010499-P2B, 010759-P2B, and 010710-P2B. In addition, we wish to acknowledge the help provided by $\mathrm{J}$ \& G Equipment in Nelson County, Kentucky for sharing information about their program with us. We are also indebted to the Kentucky Agricultural Statistics Service for their advice and assistance in conducting the two surveys described in this paper. We are also grateful to the farmers who consented to being interviewed.

\section{Authors' affiliations}

M L Myers, H P Cole, S C Westneat, Southeast Center for Agricultural Health and Injury Prevention, College of Public Health, University of Kentucky, Lexington, Kentucky, 40504-9842 USA

\section{REFERENCES}

1 Cole HP, Westneat S. The Kentucky ROPS Project. Final technical report for partners in prevention:promoting ROPS and seat belts on family farm tractors. Southeast Center for Agricultural Health and Injury Prevention, University of Kentucky, Lexington, Kentucky, 15 February 2001.

2 Myers ML. Prevention effectiveness of roll-over protective structures part I: strategy evolution. J Agric Saf Health 2000;6:29-40

3 Anonymous. Farmer killed after tractor overturns into creek bed. Final KY FACE \# 95KY04301. Lexington, Kentucky: University of Kentucky, 11 August 1995, www.kiprc.uky.edu/projects/face/data/reports/95KY043.htm (accessed 12 January 2005).

4 Freeman SA. Potential impact of a ROPS retrofit policy in central lowa. J Agric Saf Health 1999:5:11-18.

5 Snider DE, Holtgrave DR, Dunet DO. Decision analysis. In: Haddix AC, Teutsch SM, Shaffer PA, et al. Prevention effectiveness: a guide to decision analysis and economic evaluation. New York: Oxford University Press, 1996:27-45

6 Haddix AC, Shaffer PA. Cost-effectiveness analysis. In: Haddix AC, Teutsch SM, Shaffer PA, et al. Prevention effectiveness: a guide to decision analysis and economic evaluation. New York: Oxford University Press, 1996:103-29.

7 Petitti DB. Meta-analysis, decision analysis, and cost-effectiveness analysis: methods for quantitative synthesis in medicine. New York: Oxford University Press, 1994:24-8.

8 Myers ML, Pana-Cryan R. Prevention effectiveness of roll-over protective structures part II: decision analysis, J Agric Saf Health 2000;6:41-55.

9 Myers ML, Cole HP, Westneat SC. Cost-effectiveness of a ROPS retrofit education campaign. J Agric Saf Health 2004;10:77-90. 
10 Springfeldt B, Thorson J, Lee BC. Sweden's thirty-year experience with tractor rollovers. J Agric Saf Health 1998;4:173-80.

11 Cole HP, McKnight RH, Browning SR, et al. Estimates of the probability of death during farm tractor overturns. Presented at the National Occupational Injury Research Symposium, Pittsburgh, PA, 17 October 2000.

$12 \mathrm{CDC}$. A practical guide to prevention effectiveness: decision and economic analyses. Prepared by the Prevention Effectiveness Activity, Epidemiology Program Office, Centers for Disease Control and Prevention, Atlanta, Georgia 1994.

13 Leigh JP, Markowitz SB, Fahs MC, et al. Costs of occupational injuries and illnesses. Ann Arbor: The University of Michigan Press, 2000:2.

14 Brandt V, Struttmann T, Cole H, et al. Delivering health education messages for part-time framers through local employers. Appendix $\mathrm{H}$ in Cole HP, Westneat S 2001. The Kentucky ROPS Project. Final technical report for partners in prevention:promoting ROPS and seat belts on family farm tractors. Southeast Center for Agricultural Health and Injury Prevention, University of Kentucky, Lexington, Kentucky, 15 February 2001.

15 Leigh JP, McCurdy SA, Schenker MB. Costs of occupational injuries in agriculture. Public Health Rep 2001;116:235-48.

16 Pana-Cryan R, Myers ML. Prevention effectiveness of roll-over protective structures: part III, economic analysis. J Agric Saf Health 2000;6:57-70.

17 Biddle EA. The economic cost of fatal occupational injuries in the United States, 1980-97. Contemp Econ Policy 2004;22:370-81.

18 Nord E. Cost-value analysis in health care: making sense out of QALYs. New York: Cambridge University Press, 1999:23-5.

19 Pana-Cryan R, Myers ML. Cost-effectiveness of roll-over protection structures. Am J Ind Med, 2002;Suppl 3, 68-71.

\section{LACUNAE}

\section{Survey of UK children} $\mathrm{s}$ part of its work to promote active citizenship and community participation, the UK
government has recently published the findings of a survey of children aged 8-10 and

11-15 years. The report includes issues of relevance to the prevention of unintentional injuries. It notes that the main reasons that 11-15 year old children expressed reasons for feeling unsafe in the neighbourhood were the fear of abduction and stranger danger $(48 \%)$ and bullying (35\%), with traffic causing far less concern (12\%). Among 8-10 year olds, the fear of traffic was 23\%. The 130 page report by Christine Farmer, 2003 Home Office citizenship survey: top-level findings from the children's and young people's survey can be downloaded from http://www.dfes.gov.uk/research/data/uploadfiles/RW29.pdf. 